\title{
Renoprotective effect of red ginseng in gentamicin-induced acute kidney injury
}

\author{
Hyun-Soo Shin ${ }^{1}$, Mina Yu', Mijin Kim, Hack Sun Choi and Duk-Hee Kang
}

Aminoglycoside-induced nephrotoxicity is one of the prevalent causes of acute kidney injury (AKI). Oxidative stressmediated apoptosis of renal tubular cells is known to be a major mechanism of renal injury. Red ginseng extract (RGE) has been reported to possess antioxidant and immune-modulatory activities. We investigated the effect of RGE on gentamicin (GM)-induced apoptosis and oxidative stress in cultured renal tubular cells and animal model of GM-induced AKI. GM induced the generation of reactive oxygen species (ROS) with an increase in NADPH oxidase (NOX) activity and mitochondrial oxidation in NRK-52E cells that were ameliorated with RGE. GM-induced apoptosis of NRK-52E cells, which was associated with an increased expression of mitochondrial Bax, cytosolic cytochrome $c$, and cleaved caspase-9 and -3, along with a decrease in bcl-2 expression, was also blocked by RGE. In an animal model of GM-induced AKI, RGE treatment significantly attenuated renal dysfunction, cell apoptosis, and tubular damage. RGE ameliorated ROS production in rats with GM-induced AKI, as demonstrated by an increase in the reduced form of glutathione in renal cortex and a decrease in urinary excretion of 8-hydroxy-2'-deoxyguanosine. Our results suggest that RGE protects the kidney from GM-induced AKI via the mechanism of modulation of oxidative stress.

Laboratory Investigation (2014) 94, 1147-1160; doi:10.1038/labinvest.2014.101; published online 11 August 2014

Aminoglycoside antibiotics are widely used for the treatment of Gram-negative bacterial infection, and are also effective against Staphylococcus and Enterococcus. ${ }^{1,2}$ Although aminoglycoside remains the first-line antibiotic for many severe infections because of several advantages including low rate of resistance and inexpensive cost, the prescription of aminoglycoside is limited because of its nephrotoxicity. ${ }^{3,4}$ Gentamicin (GM)-induced acute kidney injury (AKI) occurs in $10-20 \%$ of treated patients, and even more in populations at risk. ${ }^{5}$ The drug is accumulated in renal epithelial cells, and causes the loss of the brush border, apoptosis, massive proteolysis, and overt necrosis of renal tubules. ${ }^{6}$ The proposed mechanism of GM-induced renal damage includes the generation of free radicals, phospholipidosis, a decrease of renal blood flow, and an induction of local inflammation. ${ }^{7-10}$ Reactive oxygen species (ROS) have been reported as one of the key mediators of GM-induced nephrotoxicity as shown by an increased production of ROS by GM and the protective effect of ROS scavengers on GM-induced necrosis of renal tubules. ${ }^{7,11,12}$

Ginseng, the root of Panax ginseng C.A. Meyer (family Araliaceae), is one of the most widely prescribed and intensely studied herbal medicines. Ginseng or its active metabolite, ginsenoside, is reported to be effective in treatment of various immune, endocrine, cardiovascular, and neurodegenerative diseases. ${ }^{13-16}$ Ginsenoside protected the kidneys from cisplatininduced renal injury via an amelioration of oxidative stress and an inhibition of DNA fragmentation. ${ }^{17}$ Ginseng extracts also inhibited the generation of ROS and apoptosis of auditory cell in cisplatin-induced ototoxicity. ${ }^{18}$ In this study, we investigated the effect of red ginseng extract (RGE, the steamed root of Panax ginseng C.A.) on renal function and pathology in animal model of GM-induced AKI with an elucidation of mechanisms for its renoprotective effect.

\section{MATERIALS AND METHODS Reagents}

All chemicals and tissue culture plates were obtained from Sigma-Aldrich (St Louis, MO, USA) and Nunc Labware (Waltham, MA, USA), unless otherwise stated. RGE was manufactured from the roots of a fresh Panax ginseng C.A. Meyer plant (Korean Ginseng and Tobacco Research Institute, Daejeon, Korea). In detail, red ginseng was made by steaming 6-year-old fresh ginseng roots at $90-100{ }^{\circ} \mathrm{C}$ for $3 \mathrm{~h}$ and then 
drying at $50-80^{\circ} \mathrm{C}$. RGE was prepared from red ginseng water extract that was extracted at $87^{\circ} \mathrm{C}$ for $8 \mathrm{~h}$ of circulating hot water six times. A voucher specimen (201-E7024) was deposited at Korea Ginseng Corporation. Active component of RGE was analyzed by high-performance liquid chromatography. ${ }^{19}$ RGE used in this experiment contains major ginsenoside-Rb1: 13.9\%, -Rb2: 14.4\%, -Rc: 6.1\%, -Rd: 13.9\%, -Re: $4.7 \%$, -Rf: 11.5\%, -Rg1: 2.6\%, -Rg2: 0.69\%, -Rg3: 2.8\%, and other minor ginsenosides. Mitochondria-target ubiquinone (MitoQ) is a kind gift from Dr Michael P Murphy (Medical Research Council Dunn Human Nutrition Unit, UK). NAPDH oxidase inhibitor (NOXi) is a gift from Professor Bae YS (Center for Cell Signaling Research, Division of Molecular Life Sciences, Ewha Womans University, Seoul, Korea).

\section{Cell Culture}

Rat renal tubular epithelial cells (NRK-52E cells) were obtained from the American Type Culture Collection (ATCC, Manassas, VA, USA). NRK-52E cells were cultured in Dulbecco's modified Eagle's medium (DMEM) supplemented with $5 \%$ fetal bovine serum (FBS). Cells were maintained at $37^{\circ} \mathrm{C}$ in a humidified $5 \% \mathrm{CO}_{2} / 95 \%$ air atmosphere incubator. A fresh medium was added to the cells every 2 days until cells reached an adequate confluency for each experiment.

\section{Cytotoxicity Assay}

Cytotoxicity of GM in NRK-52E cells was determined by the amount of lactate dehydrogenase (LDH) leaking into the medium after $48 \mathrm{~h}$ of treatment using the LDH cytotoxicity detection kit (Roche, Mannheim, Germany) according to the manufacturer's direction. Each series of data was determined in triplicate.

\section{Cell Proliferation Assay: $\left[{ }^{3} \mathrm{H}\right]$-Thymidine Incorporation}

NRK-52E cells were cultured at a concentration of $5 \times 10^{4}$ cells $/ \mathrm{ml}$ in 6-well culture plates in DMEM containing 5\% FBS. Cells were incubated with GM at $37^{\circ} \mathrm{C}$ for $48 \mathrm{~h}$, and then $\left[{ }^{3} \mathrm{H}\right]$-thymidine $(1 \mu \mathrm{Ci} / \mathrm{ml})$ was added. After washing with trichloroacetic acid and phosphate-buffered saline (PBS), cells were solubilized with 2\% SDS before quantitation of $\left[{ }^{3} \mathrm{H}\right]$ by scintillation counting (Beckman Coulter). Data from each experimental condition were determined in triplicate.

\section{Determination of the Cellular Uptake of GM}

To determine whether RGE affects intracellular uptake of GM, we quantitated intracellular GM content. NRK-52E cells were seeded at a concentration of $5 \times 10^{4}$ cells $/ \mathrm{ml}$ in 6-well culture plates with $3 \mathrm{~mm}$ GM for different time periods with or without RGE $(100 \mu \mathrm{g} / \mathrm{ml})$, washed three times with PBS, and then lysed with lysis buffer. The concentration of GM in each sample was detected using GM ELISA kits according to instructions provided by the manufacturers (Euro-Diagnostica B.V., Arnhem, The Netherlands).

\section{ROS Generation by DCF-DA Fluorescence Measurement} NRK-52E cells were incubated with $10 \mu \mathrm{m}$ of $2^{\prime}, 7^{\prime}$-dichlorofluororescein diacetate (DCF-DA) (Invitrogen, Carlsbad, CA, USA) before an exposure to GM ( $3 \mathrm{~mm})$, RGE $(100 \mu \mathrm{g} / \mathrm{ml})$ or $\mathrm{H}_{2} \mathrm{O}_{2}(100 \mu \mathrm{M})$. A serial fluorescence was measured using fluorescent plate reader at excitation $485 \mathrm{~nm}$ and emission $535 \mathrm{~nm}$ (Molecular Device).

\section{Mitochondrial ROS production}

Mitochondrial-associated ROS levels were measured by exposure of cells to $2.5 \mu \mathrm{M}$ of MitoSOX ${ }^{\mathrm{R}}$ red (Invitrogen) for $30 \mathrm{~min}$ at $37^{\circ} \mathrm{C}$. The cells were visualized under the Axiovert 200 fluorescence microscope (Carl Zeiss, Oberkochen, Germany). Number of ROS-positive cells was counted in 10 random fields at $\times 100$ magnification.

\section{Measurement of NADPH Oxidase (NOX) Activity}

NOX activity was measured by a luminescence assay of superoxide production in a $50 \mathrm{~mm}$ phosphate buffer containing $1 \mathrm{~mm}$ EGTA, $150 \mathrm{~mm}$ sucrose, $5 \mu \mathrm{m}$ lucigenin as the electron acceptor, and $100 \mu \mathrm{m} \mathrm{NADPH}$ as the donor with an addition of $100 \mu$ l of cell homogenate (100 $\mu$ g proteins). NOX activity was expressed as the rate of relative chemiluminescence units per mg of protein. Protein content was measured using the Bio-Rad protein assay reagent (Bio-Rad Laboratories, CA, USA).

\section{Cell Apoptosis Assay: Flow Cytometric Analysis for Propidium lodide Staining and Annexin V-FITC Binding} After exposure of NRK-52E cells to GM for $48 \mathrm{~h}$, cell suspensions were prepared by treating cells with trypsin/EDTA mixture in DMEM. Cells were washed twice in cold PBS, and then resuspended in $1 \times$ Annexin $\mathrm{V}$ binding buffer at a concentration of $1 \times 10^{6} \mathrm{cells} / \mathrm{ml}$. After incubation of $100 \mu \mathrm{l}$ cell suspension with $5 \mu \mathrm{l}$ FITC Annexin V and $5 \mu \mathrm{l}$ propidium iodide (PI) at room temperature in the dark for $15 \mathrm{~min}$, $400 \mu \mathrm{l}$ of $1 \times$ binding buffer was added to each tube. Samples were then analyzed on a FACS Calibur flow cytometer (Beckton Dickinson, San Jose, CA, USA) and CellQuest software (Beckton Dickinson). The 10000 events per sample were collected with an exclusion of cell debris by scatter gating (forward $v s$ side). The data were displayed as two-color dot plot with FITC-Annexin V (green fluorescence, $\mathrm{X}$ axis) vs PI (red fluorescence, $\mathrm{Y}$ axis). The Annexin $\mathrm{V}+/ \mathrm{PI}-$ cells were counted as early apoptotic cells and Annexin $\mathrm{V}+/ \mathrm{PI}+$ cells were late apoptotic cells.

\section{Western Blot Analysis}

After incubation of NRK-52E cells with GM for $48 \mathrm{~h}$, protein samples isolated from cell lysates were mixed in reducing buffer, boiled, resolved on 10\% SDS-PAGE gels, and transferred to a polyvinylidene difluoride membrane by electroblotting as 
described previously. ${ }^{20}$ Membranes were blocked in 5\% wt/vol nonfat milk powder in Tris-buffered saline for $30 \mathrm{~min}$ at room temperature. Blots were then incubated overnight in blocking solution with primary antibody at $4{ }^{\circ} \mathrm{C}$. Mouse $\mathrm{mAb}$ to Bax (Abcam, UK) and rabbit mAbs to Bcl-2, cytochrome $c$, cleaved caspase-9, and cleaved caspase-3 (Cell Signaling, Danvers, MA, USA) were used. After washing the blot with Tris-buffered saline with Tween-20, the blots were incubated with horseradish peroxidase-conjugated secondary antibodies corresponding to each primary antibody, followed by enhanced chemiluminescence detection (Santa Cruz Biotechnology). Positive immunoreactive bands were quantified by densitometry and compared with the expression of $\beta$-actin.

Isolation of Mitochondrial and Cytosolic Protein Fraction Mitochondrial and cytosolic proteins were isolated using the Mitochondria Isolation Kit (Thermo Scientific, Rockford, IL, USA) according to the manufacturer's instructions.

\section{In Vivo Experimental Model of GM-Induced AKI}

Figure 1 shows the protocol for animal model of gentamicininduced AKI. A total of 52 male Sprague-Dawley rats (200240 g; Central Lab. Animal, Seoul, Korea) were randomized into four groups (Control, RGE, GM, and GM + RGE) after measuring blood urea nitrogen (BUN), creatinine, and proteinuria: control group with vehicle injection $(n=10)$, RGE group with oral administration of RGE $(100 \mathrm{mg} / \mathrm{kg} /$ day for 30 days before GM injection and 10 days with GM, $n=10)$, GM group with intraperitoneal GM injection $(100 \mathrm{mg} / \mathrm{kg} / \mathrm{day})$ for 10 days $(n=16)$, and GM + RGE group that received RGE 30 days before and together with GM injection for 10 days $(n=16)$. Rats were killed at days 3 and 10 for evaluation of renal function and histology. BUN (QuantiChrom urea nitrogen assay kit; Bioassay Systems, Hayward, CA, USA), creatinine (QuantiChrom creatinine assay kit), and urinary protein excretion (BCA protein assay kit; Pierce Biotechnology, Rockford, IL, USA) were measured according to the standard protocol. All animal procedures were approved by the Animal Care Committees of Ewha Womans University School of Medicine. Tissue for light microscopy was fixed in Methyl Carnoy's solution and embedded in paraffin. Then, $4 \mu \mathrm{m}$ sections were stained with the periodic acid-Schiff (PAS) reagent and counterstained with hematoxylin. Tubular necrosis score $(0-4)$ was assessed on the basis of PAS staining as described previously. ${ }^{21}$ All analyses were performed blinded.

\section{TUNEL Staining}

Apoptosis of renal cells was identified by TdT-mediated dUTP nick-end labeling (TUNEL) staining. End labeling of exposed 3' $\mathrm{OH}$ ends of DNA fragments was undertaken with

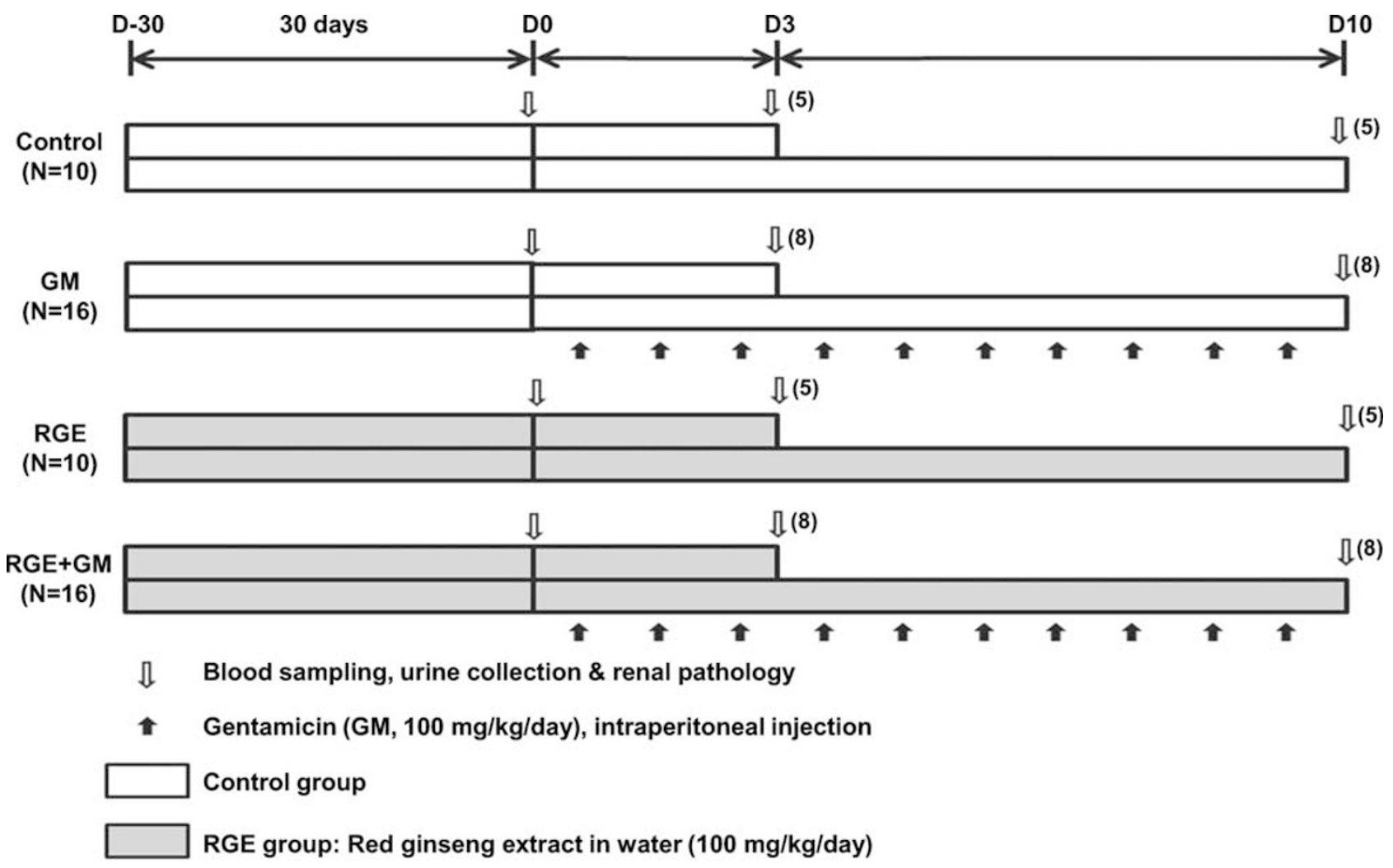

Figure 1 Animal model of GM-induced AKI. Numbers in parenthesis refer to the numbers of rats killed on day 3 (D3) and day 10 (D10). 
the TUNEL in situ cell death detection kit (Roche Diagnostics, Laval, Quebec, Canada) as described by the manufacturer. After the deparaffinization and dehydration of tissue section, nuclear proteins were stripped from the DNA by incubating in proteinase $\mathrm{K}$ for $20 \mathrm{~min}$ and endogenous peroxidase was blocked with hydrogen peroxide. Sections were incubated in a buffer containing TdT and digoxigenin-labeled dUTP, followed by digoxigenin-conjugated peroxidase treatment. TUNEL signal was observed using the DAB substrate kit (Vector Labs, Burlingame, CA, USA), and TUNEL-positive cells were counted in more than 10 high-power fields $(\times 200)$ in each stained section using a light microscope (BX51; Olympus, Tokyo, Japan).

\section{Measurement of Urinary 8-OH-dG and Reduced GSH in Renal Cortex}

To evaluate the oxidative/antioxidative status in rats, urinary 8-hydroxy-2'-deoxyguanosine (8-OH-dG) and reduced glutathione $(\mathrm{GSH})$ content in renal cortical tissue were measured using Oxidative DNA Damage ELISA Kit (Cell Biolabs, San Diego, CA, USA) and Glutathione Assay Kit (Cell Biolabs), respectively. Urine samples were centrifuged at 13000 r.p.m. for $10 \mathrm{~min}$ after thawing, and the supernatants were added to an $8-\mathrm{OH}-\mathrm{dG} / \mathrm{BSA}$ conjugate preabsorbed plate. After a brief incubation at $37^{\circ} \mathrm{C}, 8-\mathrm{OH}-\mathrm{dG}$ content was determined by a competitive ELISA. For GSH measurement, renal cortical tissues were homogenized in a volume of ice-cold buffer containing Tris $(10 \mathrm{~mm})$, diethylenetriamine pentaacetic acid (DTPA, $1 \mathrm{~mm}$ ), and phenylmethanesulphonyl fluoride (PMSF, $1 \mathrm{~mm}$; adjusted to $\mathrm{pH}$ 7.4). The whole homogenate was diluted (5:1) with ice-cold 5\% metaphosphoric acid, and reduced/oxidized GSH contents were measured in supernatant after centrifugation at $800 \mathrm{~g}$ for $10 \mathrm{~min}$ at $4{ }^{\circ} \mathrm{C}$. GSH was normalized by total protein contents.

\section{Statistical Analysis}

All data are presented as mean \pm s.d. Differences in parameters at each time point and the concentration of GM or RGE were compared by paired $t$-test and one-way ANOVA. Differences in the various parameters among groups were evaluated by one-way ANOVA followed by Turkey's multiple comparison. Significance was defined as $P<0.05$.

\section{RESULTS}

Effect of GM and RGE on Proliferation and Cytotoxicity of Renal Tubular Cells

GM did not impose a significant effect on cell proliferation and LDH release in NRK-52E cells up to $3 \mathrm{~mm}$ at $48 \mathrm{~h}$, whereas $10 \mathrm{~mm}$ of GM inhibited the proliferation and induced LDH release in NRK-52E cells (Figure $2 \mathrm{a}$ and $\mathrm{b}$ ). RGE at a concentration of $\geq 100 \mu \mathrm{g} / \mathrm{ml}$ ameliorated GM-induced cytotoxicity and inhibition of cell proliferation at $48 \mathrm{~h}$. There was no significant effect of 10 or $50 \mu \mathrm{g} / \mathrm{ml}$ of RGE on GM-induced changes in cell proliferation and LDH release in NRK-52E cells (Figure $2 \mathrm{c}$ and $\mathrm{d}$ ).

\section{Effect of RGE on GM-Induced ROS Production and NOX Activation}

GM (3 mM) significantly increased the ROS generation (Figure $3 \mathrm{a}$ and $\mathrm{b}$ ) and NOX activity (Figure 3c) in NRK-52E cells from $30 \mathrm{~min}$. RGE $(100 \mu \mathrm{g} / \mathrm{ml})$ significantly inhibited both ROS generation and NOX activity in GM-treated renal tubular cells. Importantly, RGE also ameliorated $\mathrm{H}_{2} \mathrm{O}_{2}$-induced increase in DCF-DA staining (Figure $3 a$ and $b$ ), suggesting the role of RGE as an antioxidant.

\section{Effect of RGE on GM-Induced Mitochondrial ROS Production}

In addition to an increase in NOX activity, GM also increased mitochondrial ROS production in NRK-52E cells. Mitochondrial ROS generation assessed by MitoSox staining was evident from $6 \mathrm{~h}$ of GM exposure that was ameliorated by RGE (Figure 4). NOXi $(1 \mu \mathrm{M})$ also decreased mitochondrial ROS production in GM-treated renal tubular cells.

\section{Effect of RGE on Apoptosis and Apoptosis-Related Protein Expression}

GM induced both an early and late apoptosis of NRK-52E cells at $48 \mathrm{~h}$ of stimulation (2.7 vs $47.6 \%$, control vs GM, $P<0.05)$. RGE significantly ameliorated GM-induced apoptosis of NRK-52E cells (Figure $5 \mathrm{a}$ and $\mathrm{b}$ ).

To understand the mechanism of GM-induced apoptosis, we examined the changes in apoptosis-associated proteins including mitochondrial Bax, cytosolic cytochrome $c$, cleaved caspase- 9 and -3 , and Bcl-2. GM increased the expression of pro-apoptotic proteins, mitochondrial Bax, cytosolic cytochrome $c$, and cleaved caspase- 9 and -3 , whereas it decreased the expression of anti-apoptotic protein $\mathrm{Bcl}-2$ from $6 \mathrm{~h}$ $(P<0.05$ vs control). Importantly, treatment with RGE $(100 \mu \mathrm{g} / \mathrm{ml})$ significantly blocked the GM-induced alteration in expression of Bax, cytochrome $c$ and cleaved caspase, and Bcl-2 $(P<0.05 v s$ GM-treated cell), suggesting that the protective effect of RGE on GM-induced apoptosis in NRK-52E cells was associated with an altered expression of apoptosisassociated proteins (Figure 6).

\section{Effect of RGE on Intracellular Uptake of GM}

To evaluate the mechanism of the protective effect of RGE on GM-induced ROS and apoptosis, the influence of RGE on the cellular uptake of GM was monitored. After GM treatment, cytosolic GM concentration reached a maximum level within $30 \mathrm{~min}$. RGE $(100 \mu \mathrm{g} / \mathrm{ml})$ did not influence the concentration of cytosolic GM (Figure 7). This finding suggests that the effect of RGE on GM-induced changes in renal tubular cells is not related to the interference in cellular uptake of GM.

\section{Effect of Antioxidants on GM-Induced Apoptosis}

We also evaluated the effect of antioxidants $\mathrm{N}$-acetyl cysteine (NAC, $5 \mathrm{~mm})$, NOXi $(1 \mu \mathrm{M})$, and MitoQ $(1 \mu \mathrm{M})$ on apoptosis and the changes in apoptosis-associated genes induced by GM. Treatment with antioxidants significantly blocked the 
a

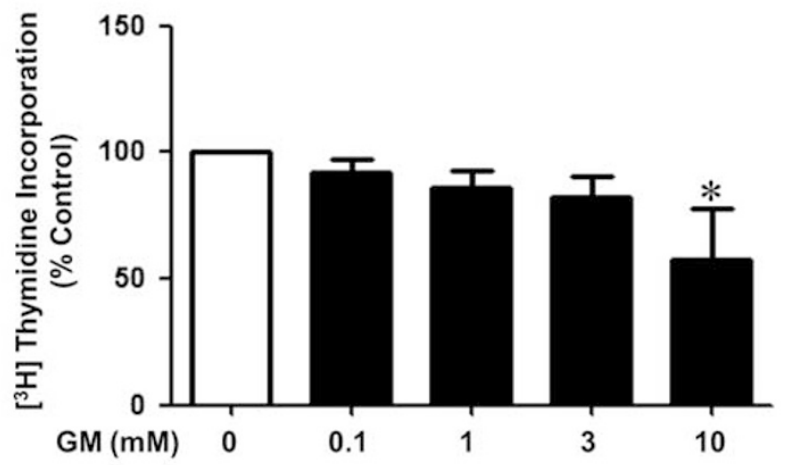

C

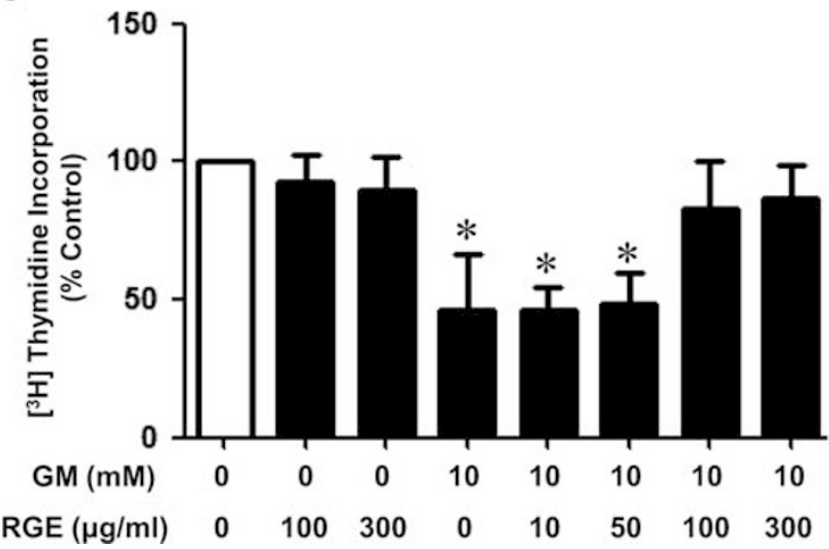

b

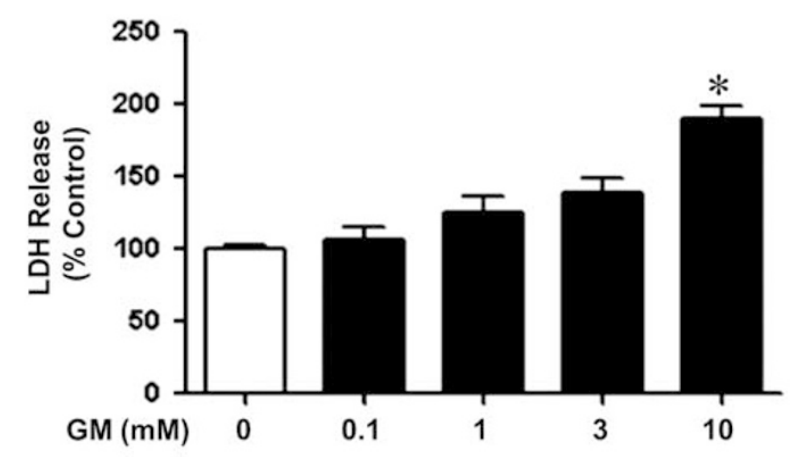

d

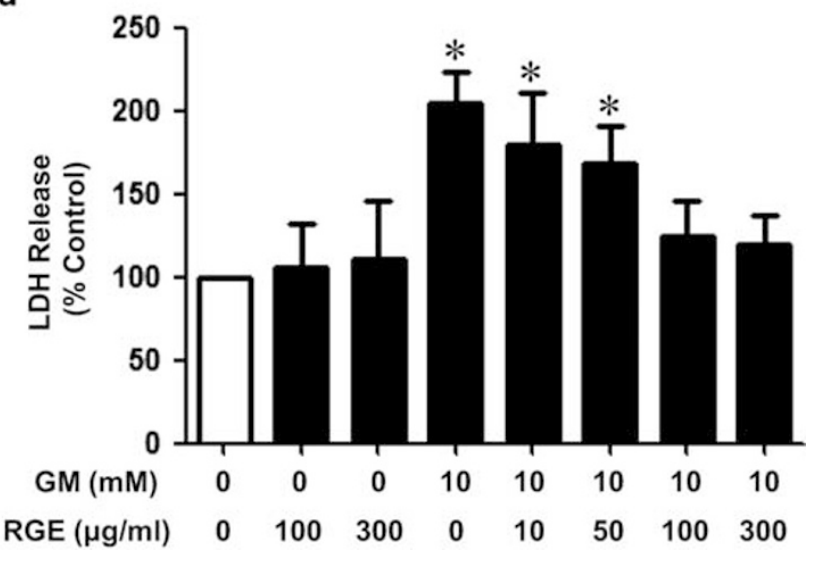

Figure 2 Effect of RGE on GM-induced changes in cell proliferation and cytotoxicity in renal tubular cells. GM (10 mM) decreases [ ${ }^{3} \mathrm{H}$ ]-thymidine uptake of NRK-52E cells with an induction of LDH release at $48 \mathrm{~h}(\mathbf{a}, \mathbf{b})$, whereas GM at concentrations of $\leq 3 \mathrm{~mm}$ does not impose a significant effect on cell proliferation and cytotoxicity. RGE (100 and $300 \mu \mathrm{g} / \mathrm{ml})$ ameliorates the inhibition of cell proliferation and cytotoxicity induced by GM at $48 \mathrm{~h}$ (c, d). Statistical analysis is performed using one-way ANOVA. Data are derived from four independent experiments and presented as the mean \pm s.d. ${ }^{*} P<0.05$ vs others.

a

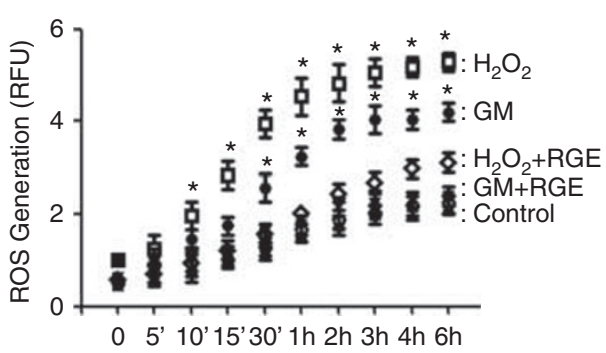

b

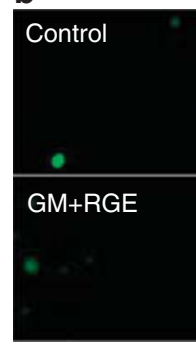

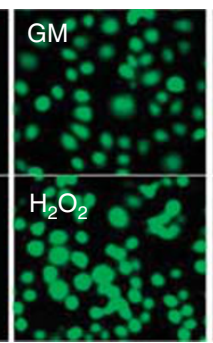

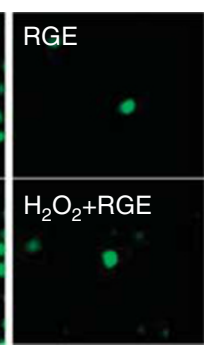

c

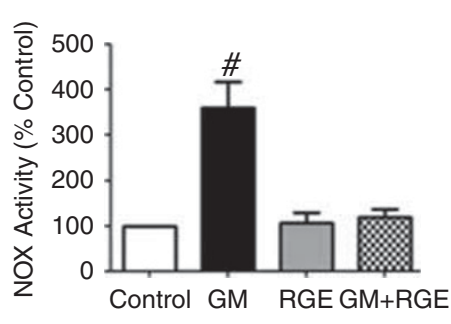

Figure 3 Effect of RGE on GM-induced ROS production and NOX activity. GM at concentration of 3 mM significantly increases the generation of intracellular ROS in NRK-52E cell from $30 \mathrm{~min}$ that is blocked by cotreatment with RGE (100 $\mu \mathrm{g} / \mathrm{ml})(\mathbf{a})$. Representative DCF-DA staining at 30 min of GM treatment is shown in (b). RGE also blocks $\mathrm{H}_{2} \mathrm{O}_{2}$-induced increase in oxidative stress $(\mathbf{a}, \mathbf{b})$. An enhanced NOX activity by $\mathrm{GM}$ at 30 min is ameliorated by RGE (c). Statistical analysis is performed using one-way ANOVA Data are derived from four independent experiments and presented as the mean \pm s.d. ${ }^{*} P<0.05$ vs other time points at each experimental condition and other experimental condition at each time point, ${ }^{\#} P<0.05$ vs others.

GM-induced alteration in the expression of mitochondrial Bax, cytosolic cytochrome c, cleaved caspase-9 and -3 , and $\mathrm{Bcl}-2$ in NRK-52E cells $(P<0.05$ vs GM-treated cells; Figure 9). NAC, NOXi, and MitoQ ameliorated GM-induced apoptosis of NRK-52E cells (Figures 8 and 9). These findings suggested the role of ROS generation via both NOX activation and mitochondrial dysfunction in GM-induced apoptosis of renal tubular cells. 


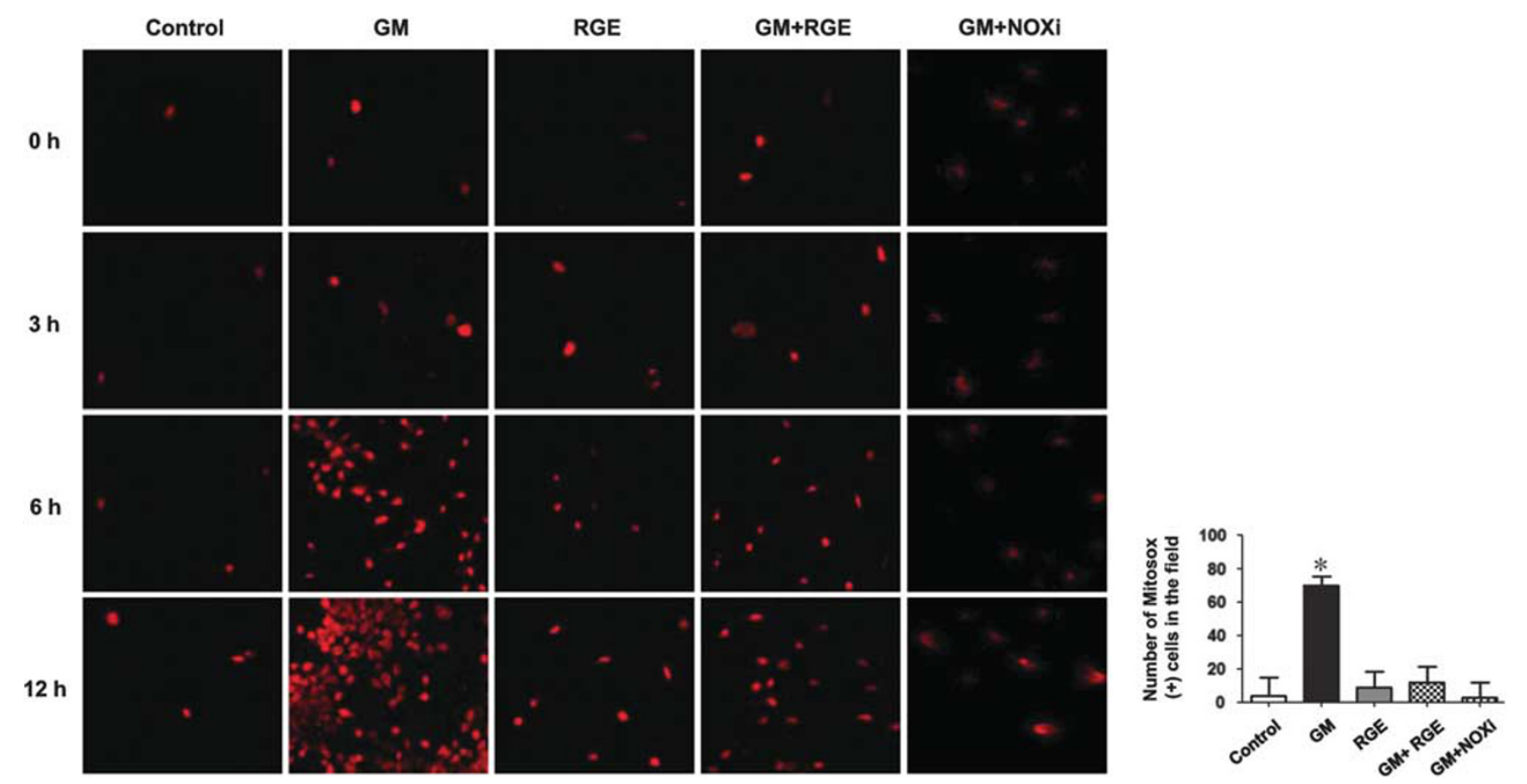

Figure 4 Effect of RGE on GM-induced mitochondrial ROS production. GM (3 mM) induces mitochondrial ROS production in NRK-52E cells from $6 \mathrm{~h}$ that is ameliorated by RGE $(100 \mu \mathrm{g} / \mathrm{ml})$ or NOX inhibitor (NOXi, $1 \mu \mathrm{m})$. Representative Mito-SOX staining with quantitation bar is shown. Statistical analysis was performed using one-way ANOVA. Data are derived from four independent experiments and presented as the mean \pm s.d. ${ }^{*} P<0.05$ vs others.
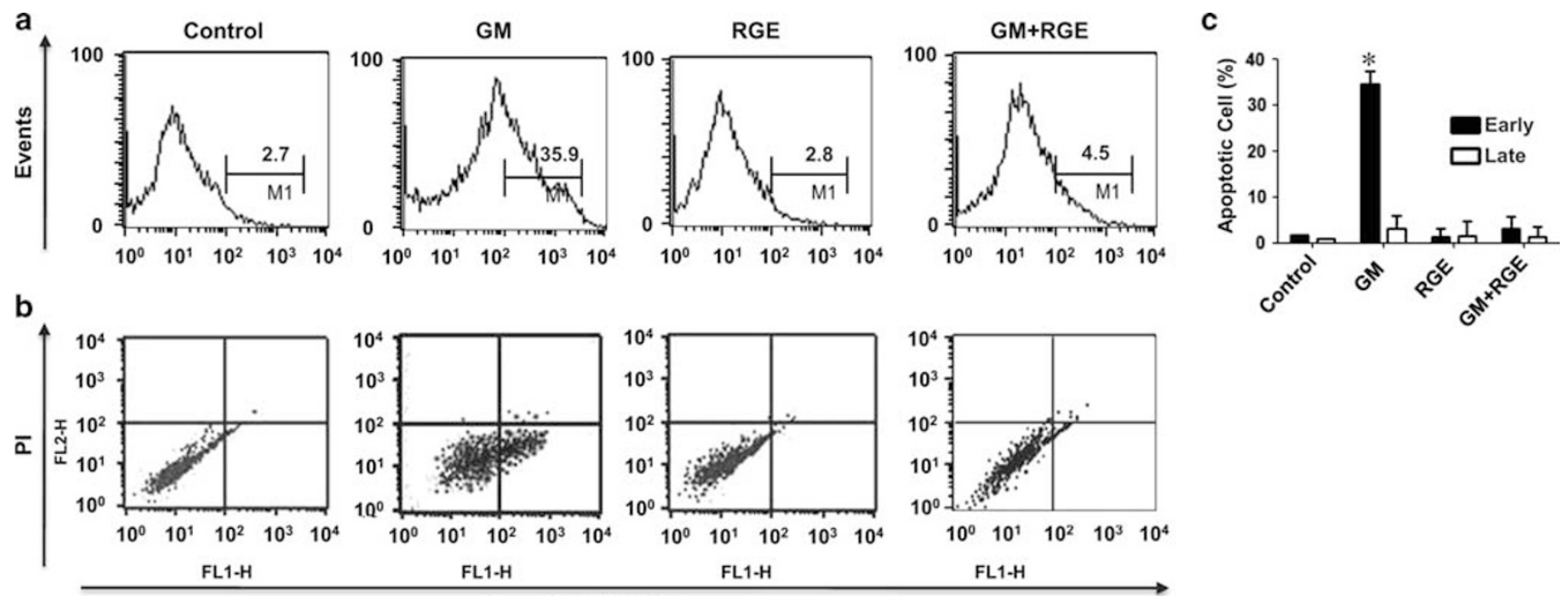

Annexin V-FITC fluorescence

Figure 5 Effect of RGE on apoptosis of renal tubular cells. GM (3 mM) induces apoptosis in NRK-52E cells. Representative histogram (a) and dot blots (b) depict the shift in fluorescence intensity of Annexin $\mathrm{V}$ binding at $48 \mathrm{~h}$. Annexin $\mathrm{V}$ and propidium iodide (PI) double staining reveals a significant increase in both early and late apoptosis in cells treated with GM, which is significantly decreased with treatment of RGE (100 $\mu \mathrm{g} / \mathrm{ml})(\mathbf{c})$. Statistical analysis is performed using one-way ANOVA. Data are derived from five independent experiments and presented as the mean $\pm s$.d. ${ }^{*} P<0.05$ vs other conditions.

\section{Effect of RGE in Animal Model of GM Nephrotoxicity}

Animal model of GM-induced AKI was generated by intraperitoneal injection of GM with or without RGE administration (Figure 1). An increase in urinary protein excretion was observed on day 3 of GM injection. BUN and creatinine were increased at 10 days of GM injection with substantial histologic changes such as tubular necrosis and dilatation (Figures 10 and 11). Rats in GM + RGE group showed an 

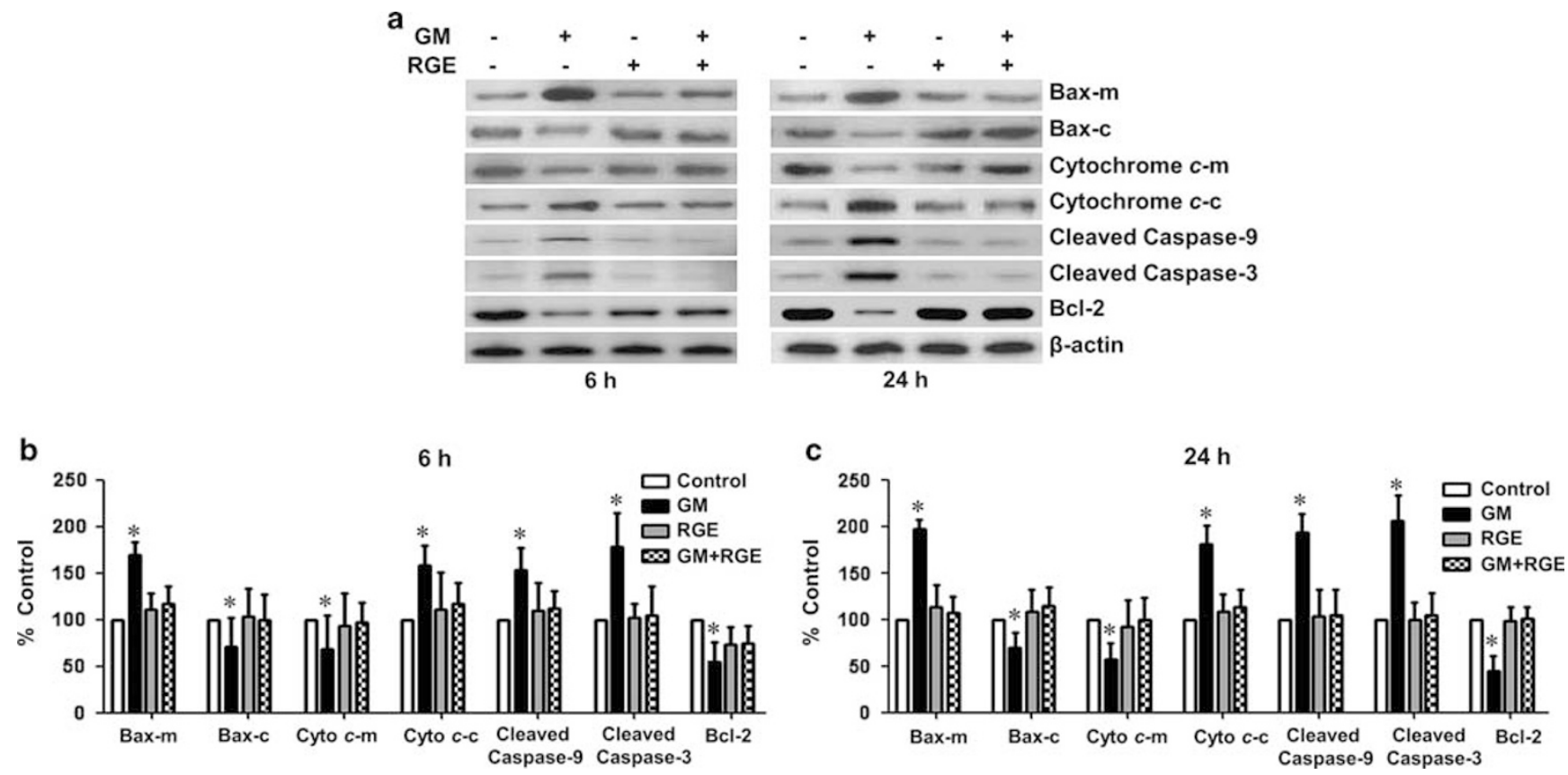

Figure 6 Effect of RGE on Bax, cytochrome $c$, caspase, and Bcl-2 expression. GM (3 mM) induces an increase of pro-apoptotic protein, mitochondrial Bax (Bax-m), cytosolic cytochrome $c$ (Cyto $c-c)$, and cleaved caspase-3 and -9, with a decrease in anti-apoptotic protein Bcl-2 in NRK-52E cells from $6 \mathrm{~h}$. RGE blocks the changes of apoptosis-related protein by GM. Representative western blots (a) and quantitation graph at 6 and $24 \mathrm{~h}(\mathbf{b}, \mathbf{c})$ are shown. $\beta$-Actin is used as control. Statistical analysis is performed using one-way ANOVA. Data are derived from three independent experiments and presented as the mean \pm s.d. ${ }^{*} P<0.05$ vs others at each protein.

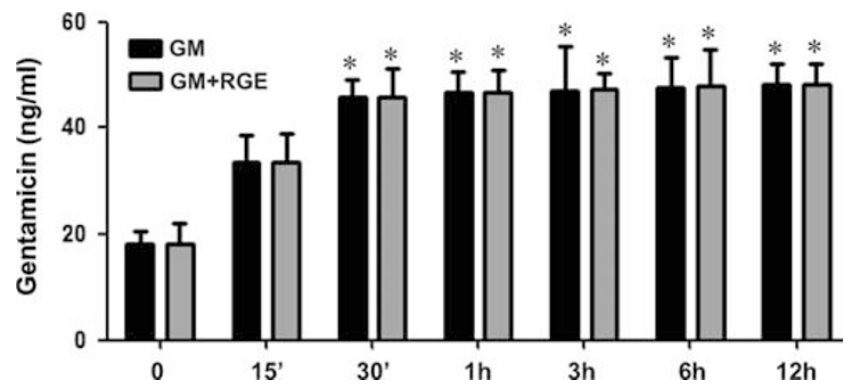

Figure 7 Effect of RGE on cellular uptake of GM. Intracellular uptake of GM is significantly increased at $30 \mathrm{~min}$ in NRK cells, and is not altered by RGE treatment up to $12 \mathrm{~h}$ of exposure. Statistical analysis is performed using one-way ANOVA. Data are derived from three independent experiments and presented as the mean \pm s.d. ${ }^{*} P<0.05$ vs intracellular $\mathrm{GM}$ at 0 and $15 \mathrm{~min}$.

amelioration of functional and histologic damage compared with the rats of GM group (Figures 10 and 11). An increase in tubular cell apoptosis assessed by TUNEL staining at 3 and 10 days of GM administration was alleviated in GM + RGE group (Figure 12). Rats in GM group demonstrated an increase in the expression of pro-apoptotic proteins, Bax, cytochrome $c$, and cleaved caspase- 9 and -3 , with a decrease in anti-apoptotic protein, Bcl-2. In GM + RGE group, there was a partial reversal of altered expression of apoptosis-related protein induced by GM (Figure 13).

\section{Effect of RGE on ROS Generation in Rats of GM Nephrotoxicity}

The GM group demonstrated an increased urinary excretion of oxidative stress marker 8-OH-dG from 3 days with a decrease in renal expression of reduced GSH, an important cellular defense against oxidative stress (Figure 14). Consistent with the in vitro effect of red ginseng, GM $+\mathrm{RGE}$ group demonstrated an amelioration of oxidative stress induced by GM, as evidenced by a decrease in urinary $8-\mathrm{OH}-\mathrm{dG}$ with an increase in renal GSH contents, as compared with GM group (Figure 14).

\section{DISCUSSION}

In this study, we demonstrated that GM induced oxidative stress in both in vitro and in vivo experimental models and red ginseng significantly ameliorated GM-induced ROS production. This antioxidant effect of red ginseng was associated with the protection of renal tubular cells from apoptosis that resulted in a significant amelioration of GM-induced AKI.

GM is a widely prescribed aminoglycoside for the treatment of Gram-negative bacteria. ${ }^{1}$ However, the clinical utility of GM is limited by the risk of ototoxicity and nephrotoxicity. ${ }^{6,22}$ Among several explanations proposed as the mechanism of GM-induced nephrotoxicity, GM-induced oxidative stress and apoptosis of renal tubular cells are regarded as major mechanisms. ${ }^{23,24}$ Panax ginseng C.A. Meyer has been used for more than 2000 years in Asia as a 
a
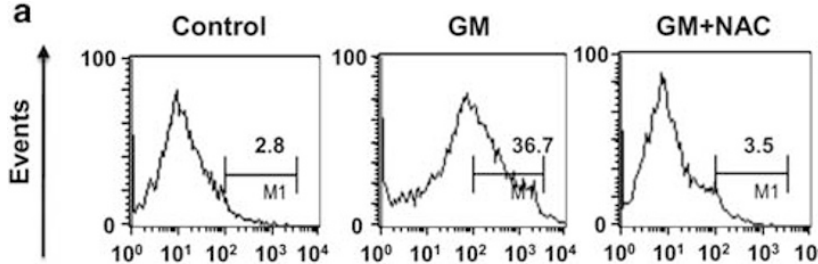

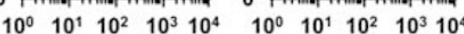
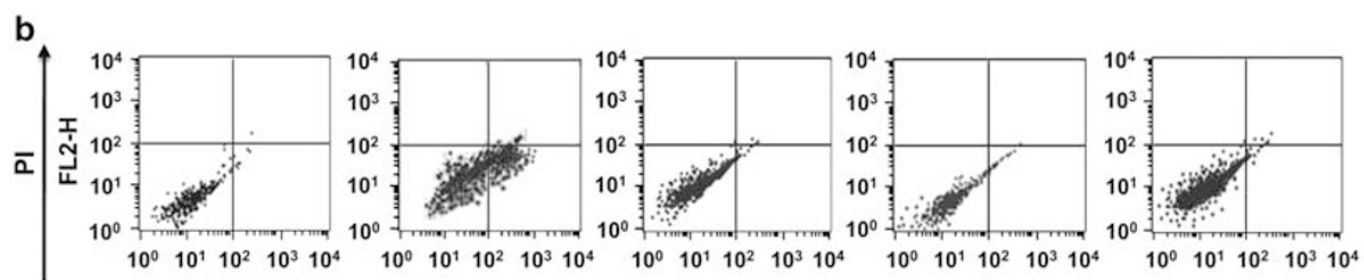

FL1-H

FL1-H

FL1-H

FL1-H

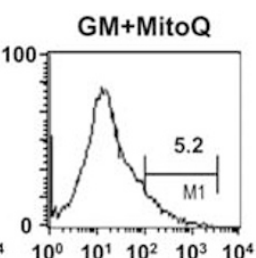

Annexin V-FITC fluorescence

Figure 8 Effect of antioxidants on GM-induced apoptosis of renal tubular cells. GM-induced apoptosis is significantly ameliorated with treatment of antioxidants, $\mathrm{N}$-acetyl cysteine (NAC, $5 \mathrm{~mm}$ ), NOX inhibitor (NOXi, $1 \mu \mathrm{m})$, and MitoQ $(1 \mu \mathrm{m})$ at $48 \mathrm{~h}$. Representative histogram (a) and dots blot (b) of FACS analysis with quantitation graph for early and late apoptotic cells based on Annexin $\mathrm{V}$ and propidium iodide (PI) double staining are shown. Statistical analysis is performed using one-way ANOVA. Data are derived from four independent experiments and presented as the mean $\pm \mathrm{s}$.d. ${ }^{*} P<0.05$ vs others.

a

b

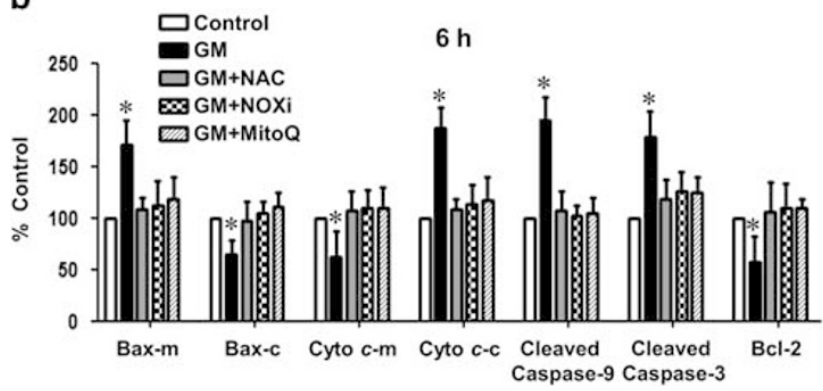

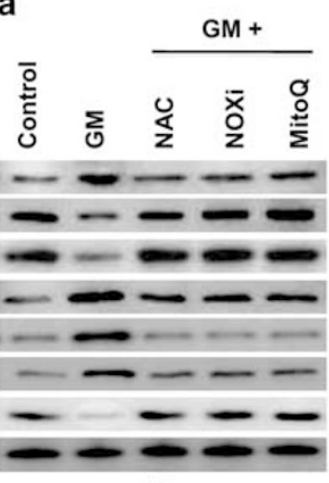

$6 \mathrm{~h}$

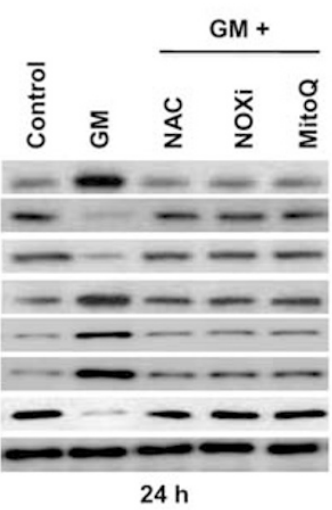

C

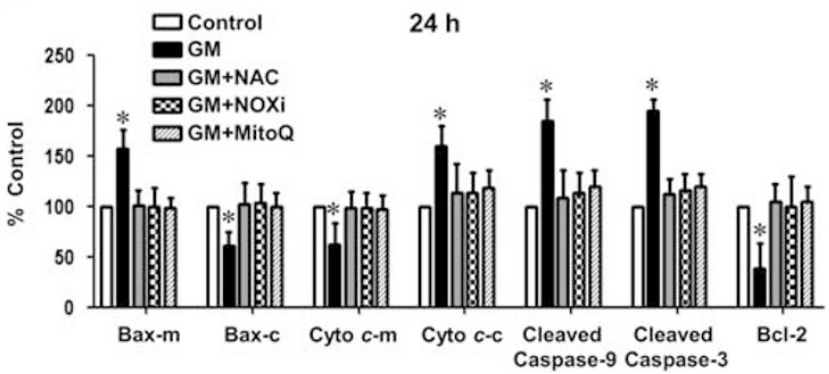

Figure 9 Effect of antioxidants on GM-induced changes in apoptosis-related proteins. GM-induced changes in mitochondrial Bax (Bax-m), cytosolic cytochrome $c$ (Cyto c-c), cleaved caspase-3 and -9, and Bcl-2 are blocked by antioxidants, $N$-acetyl cysteine (NAC, 5 mM), NOX inhibitor (NOXi, $1 \mu \mathrm{M}$ ), and MitoQ $(1 \mu \mathrm{m})$ at 6 and $24 \mathrm{~h}$. Representative western blots (a) and quantitation graph at 6 and $24 \mathrm{~h}(\mathbf{b}, \mathbf{c})$ are shown. $\beta$-Actin is used as control. Statistical analysis is performed using one-way ANOVA. Data are derived from three independent experiments and presented as the mean \pm s.d. ${ }^{*} P<0.05 v s$ others at each protein.

traditional medicine. Ginseng saponin is a major component of ginseng extract, and a glycoside of ginseng saponin known specifically as ginsenoid is regarded as an active component responsible for various beneficial effects of ginseng. ${ }^{25-28}$ Red ginseng is produced by steaming and drying fresh ginseng, which results in chemical changes of ginsenoids are reported 
a

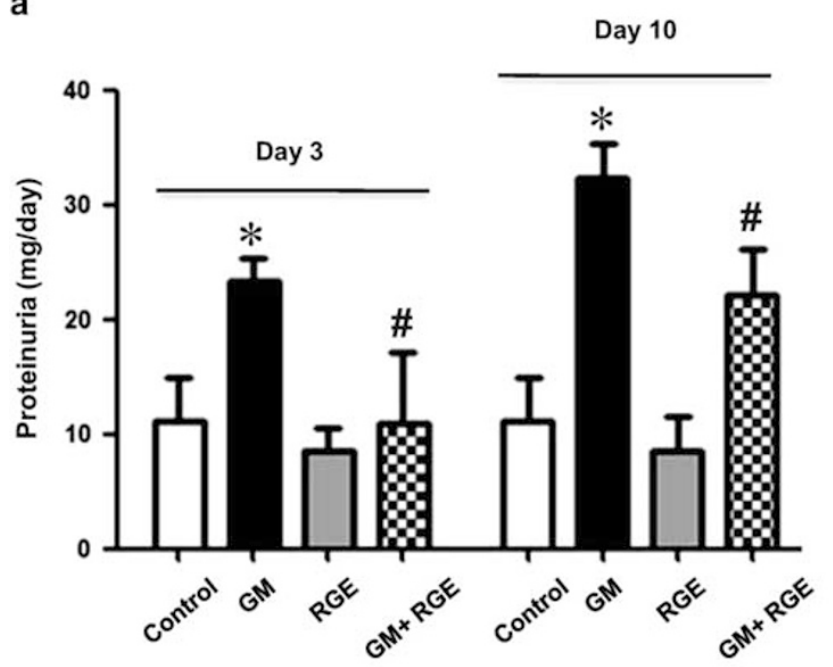

b

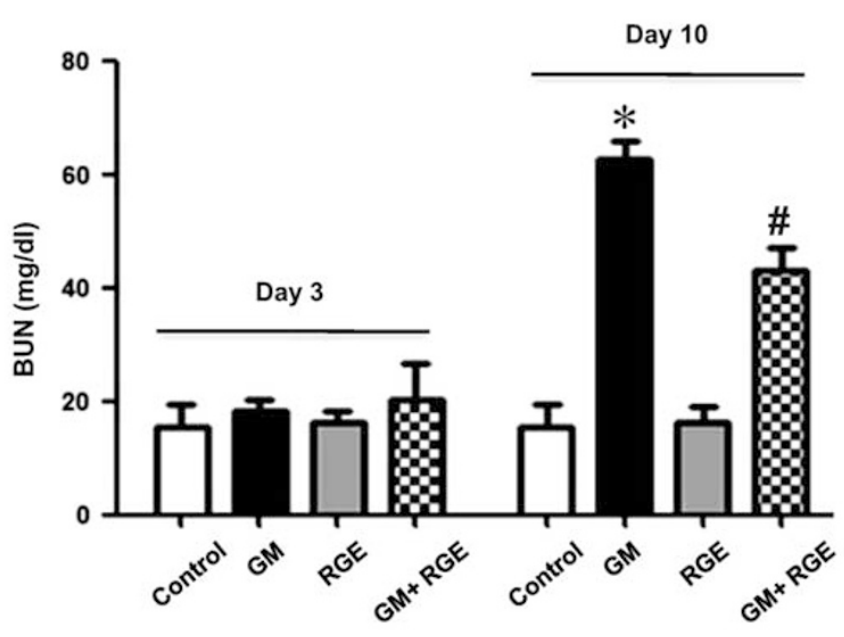

d

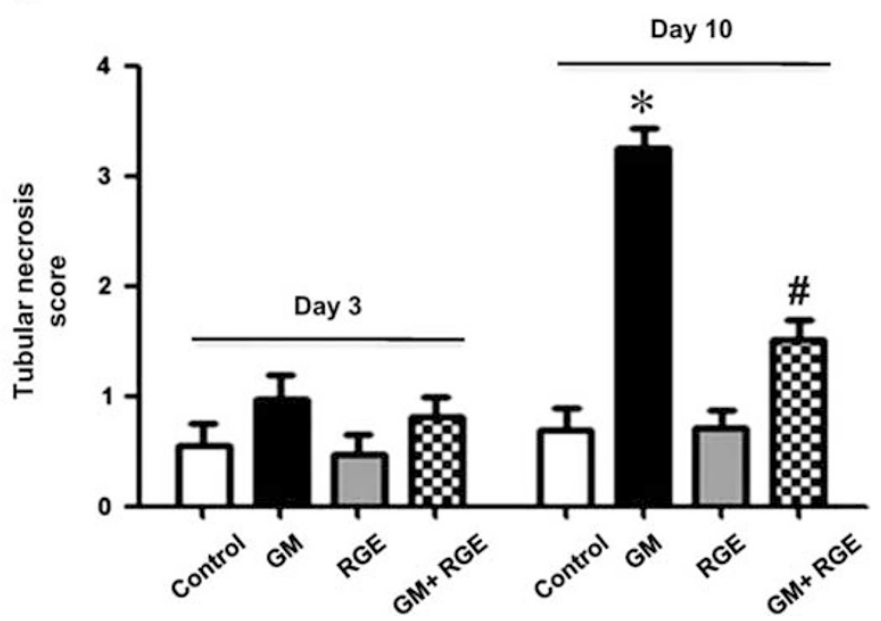

Figure 10 Effect of RGE on proteinuria, renal function, and tubular necrosis in GM-induced AKI. Increased proteinuria is noted in 3 days of GM administration (a). Blood urea nitrogen (BUN) (b) and creatinine (c) are increased in GM group on day 10. Tubular necrosis (d) is also evident on day 10. In GM + RGE group, renal function and tubular integrity are significantly preserved compared with GM group. Statistical analysis is performed using one-way ANOVA followed by multiple comparison. ${ }^{*} P<0.05$ vs other groups at each day, ${ }^{\#} P<0.05$ vs GM group on day 10 .
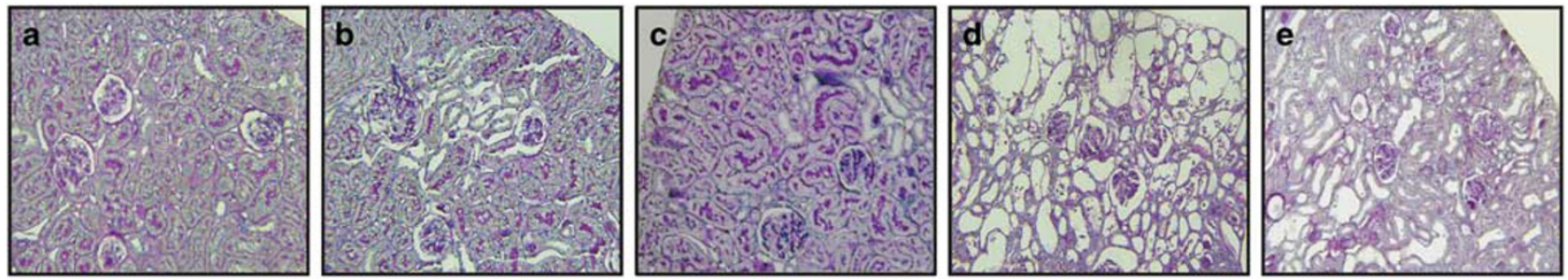

Figure 11 Effect of RGE on renal pathology in GM-induced AKI. Periodic acid-Schiff staining demonstrates focal tubular dilatation at day 3 of GM administration (b) and marked tubular damage at day 10 (d) compared with control rats (a). Rats in GM + RGE group on day 3 (c) and day 10 (e) show a significant amelioration of tubular damage compared with GM group (b, d).

to show diverse clinical activities including anticancer, hypoglycemic, vasodilatory, and anti-inflammatory effect. ${ }^{13,29-31}$ Interestingly, many of these are known to be mediated by the antioxidant effect of red ginseng. ${ }^{32,33}$
Recent studies demonstrated the renoprotective effect of ginseng in GM-induced renal injury. ${ }^{34-36}$ However, all of those studies examined the effect of RGE only in animal model of GM-induced AKI without an extensive mechanistic 

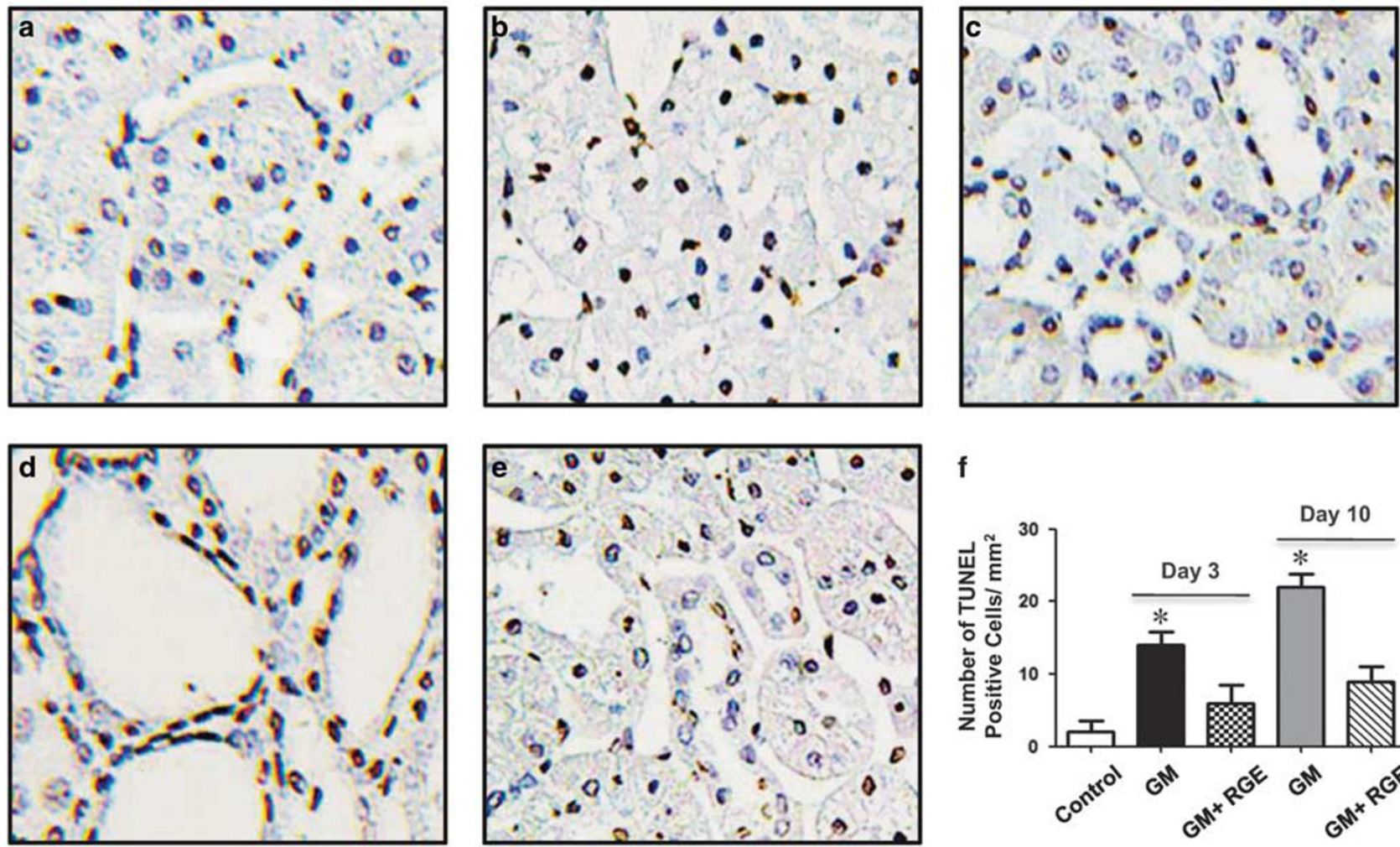

f

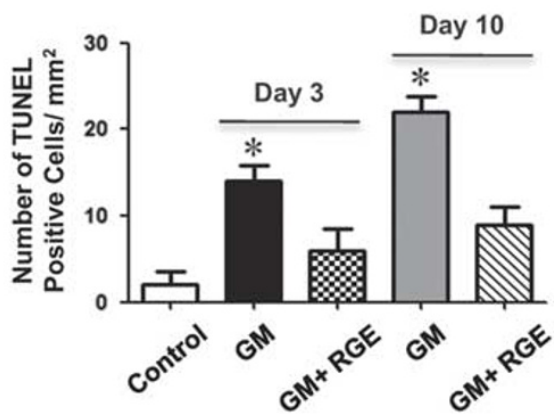

Figure 12 Effect of RGE on tubular apoptosis in GM-induced AKI. GM induces apoptosis of renal tubular cells as assessed by TUNEL staining at day 3 (b) and day 10 (d) that is ameliorated in GM + RGE group at day 3 (c) and day 10 (e). TUNEL-positive cells are counted under a high-power-field (HPF) light microscope $(\times 200)$ in more than 10 fields and averaged. Quantitation bar of apoptotic cells is shown (f). Statistical analysis is performed using one-way ANOVA. ${ }^{*} P<0.05$ vs others at each day.

analysis in in vitro model using cultured renal tubular cell that is the most important target of GM-induced damage by drug accumulation. In addition, none of previous studies investigated the antioxidant effect of RGE as a potential mechanism for renoprotection in GM-induced AKI.

One of the most important findings of this study is the antioxidative effect of RGE that inhibits both NOX-derived and mitochondrial ROS generation by GM. RGE blocked NOX activity that was enhanced in renal tubular cells exposed to GM. There were several reports demonstrating the antioxidant effect of red ginseng in cancer cells, pancreatic $\beta$ cells, auditory cells, and gastric epithelial cells, ${ }^{18,32,37,38}$ and recent studies showed the attenuation of mitochondrial dysfunction by red ginseng. ${ }^{39,40}$ Ginsenoid restored respiratory chain complex activities and aconitase activity in an animal model of focal cerebral ischemia with a decrease in mitochondrial ROS production, ${ }^{40}$ suggesting the neuroprotective effect of red ginseng via an integrated process of mitochondrial protection. In this study, one of the earliest changes in GM-treated renal tubular cells was ROS generation by NOX activation that was seen as early as at $30 \mathrm{~min}$, whereas mitochondrial ROS production by GM became evident at $6 \mathrm{~h}$ of stimulation. Interestingly, NOX inhibitors significantly ameliorated GM-induced ROS production by mitochondrial pathway (Figure 4), suggesting initial ROS generated by NOX also induced mitochondrial ROS production. The antioxidant effect of RGE was also confirmed in animal model of GM-induced AKI in this study. RGE restored the balance of oxidative stress shown as an increase of GSH level in the kidney with a reduction in urinary 8-OH-dG, a key biomarker of cellular oxidative stress. ${ }^{41,42}$ Importantly, RGE also alleviated $\mathrm{H}_{2} \mathrm{O}_{2}$-induced oxidative stress in renal tubular cells (Figure 3), suggesting the role of RGE as an antioxidant.

Another important finding of this study is the effect of RGE on GM-induced apoptosis. Apoptosis in NRK-52E cells exposed to GM was associated with an activation of mitochondrial Bax and cytosolic release of cytochrome $c$ that was evident from $6 \mathrm{~h}$ of GM treatment. Cytochrome $c$ release is known to be essential for the generation of the apoptosome-containing procaspase- 9 that initiates the effector caspase cascade including caspase- $3 .{ }^{43}$ Increased cytosolic cytochrome $c$ in our study indicated that GM-induced apoptosis of renal tubular cells occurred through mitochondrial pathway. Anti-apoptotic multidomain Bcl-2 family protein is known to regulate cytochrome $c$ release by binding the outer membrane of mitochondria and blocking the efflux of cytochrome $c{ }^{44}$ RGE ameliorated GM-induced apoptosis of 
a
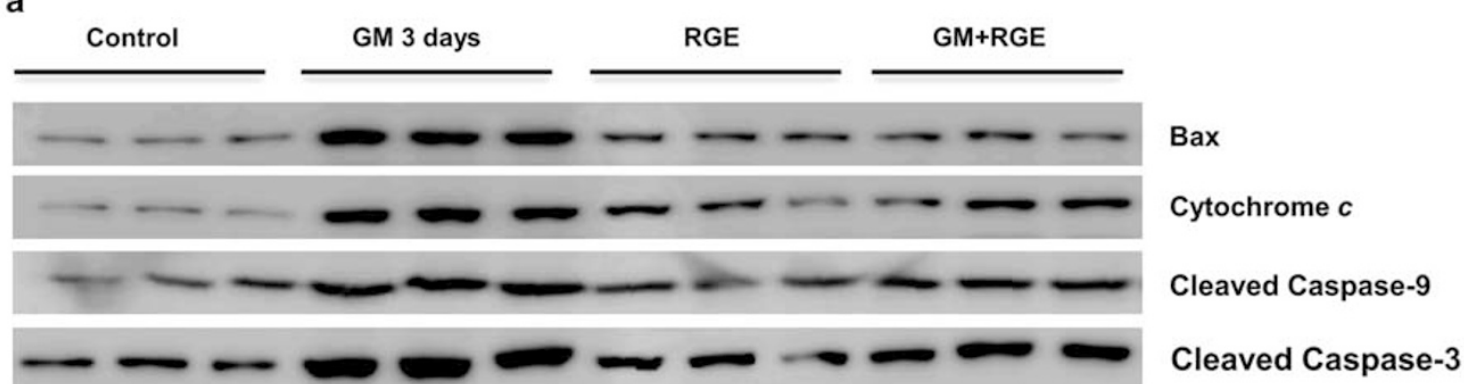

Bcl-2

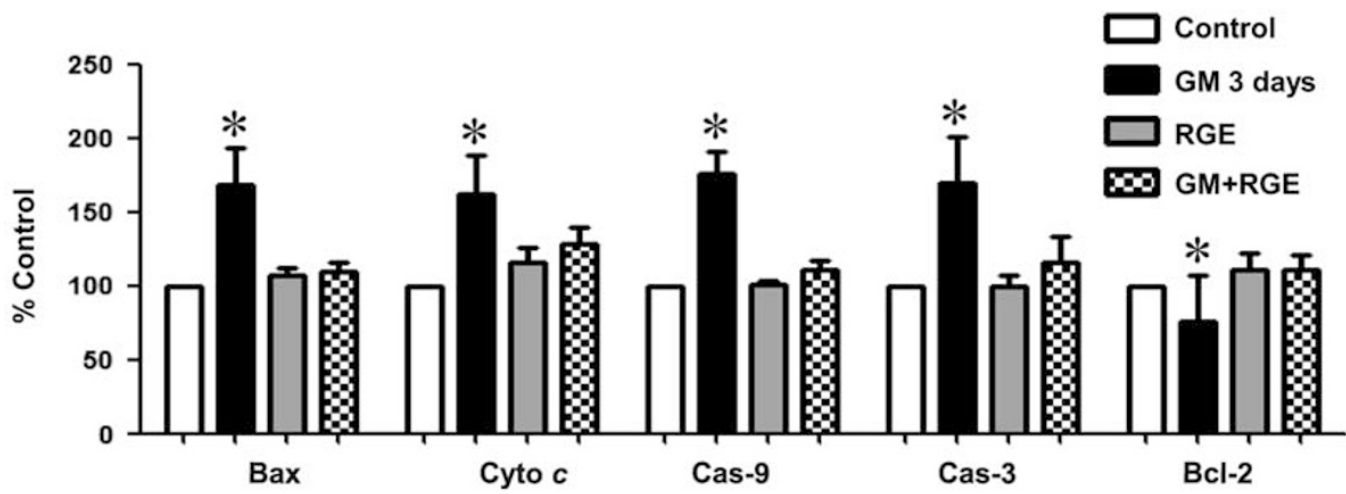

b
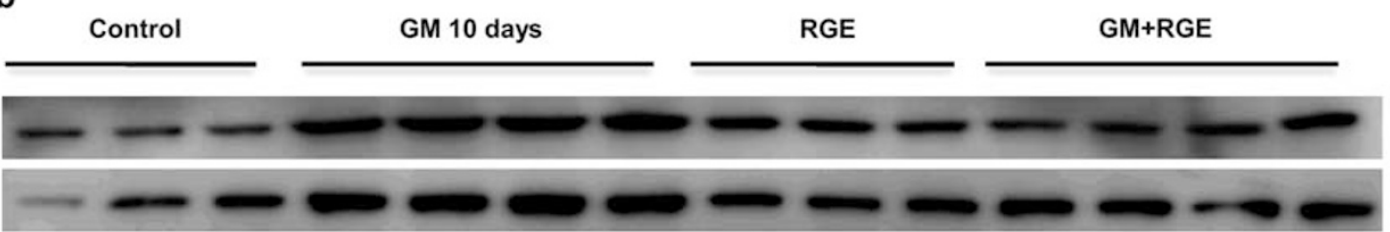

Bax

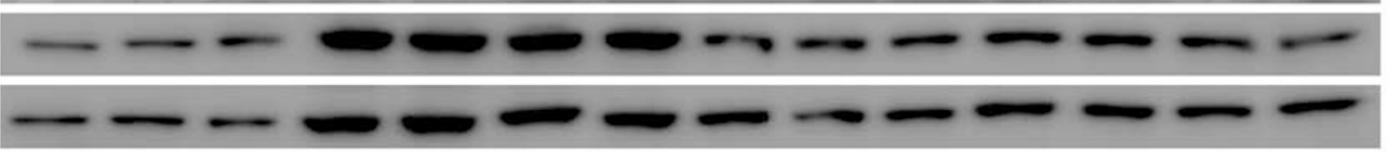

Cytochrome $c$

Cleaved Caspase-9

Cleaved Caspase-3

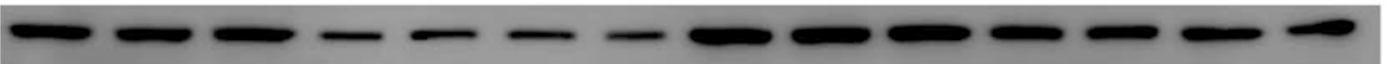

$\mathrm{Bcl}-2$

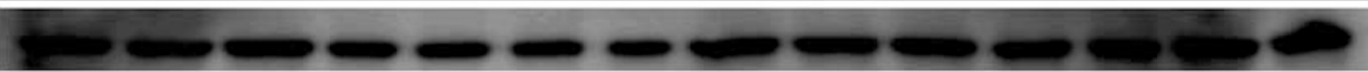

$\beta$-actin

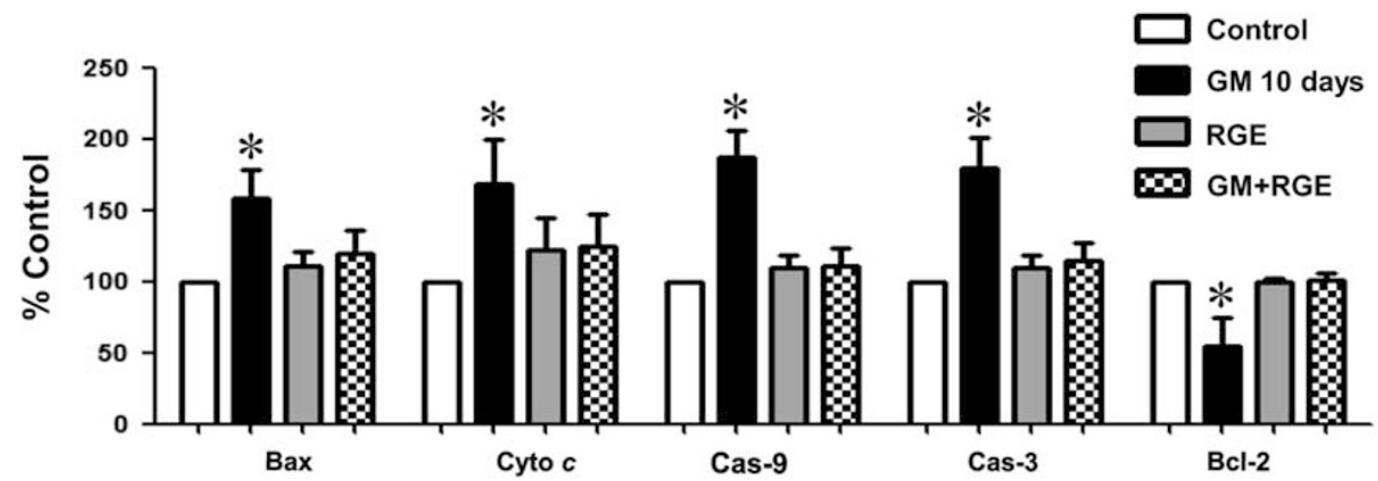

Figure 13 Effect of RGE on apoptosis in GM-induced AKI. Western blots and quantitation graph are shown (a, b). $\beta$-Actin is used as control. Statistical analysis is performed using one-way ANOVA. ${ }^{*} P<0.05$ vs others at each protein. 
a

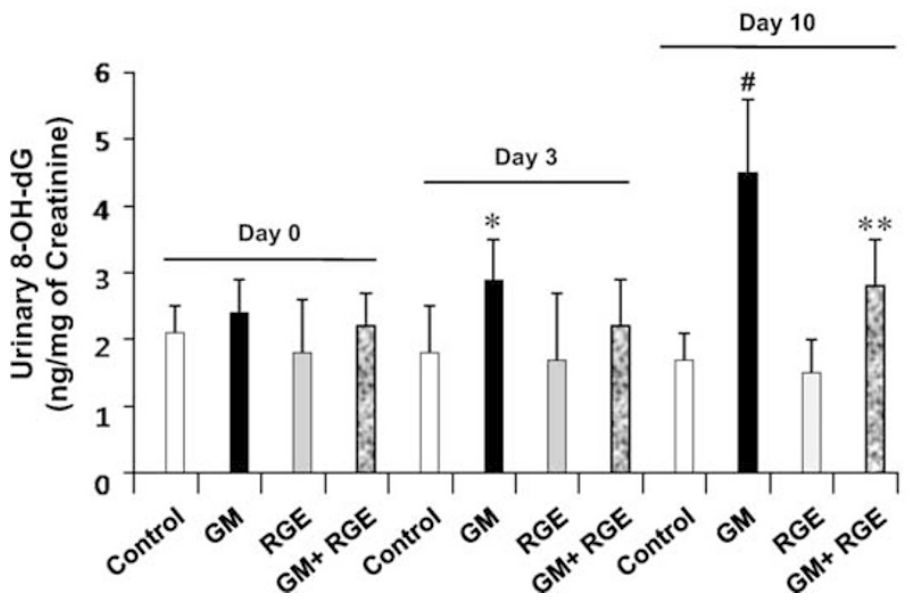

b

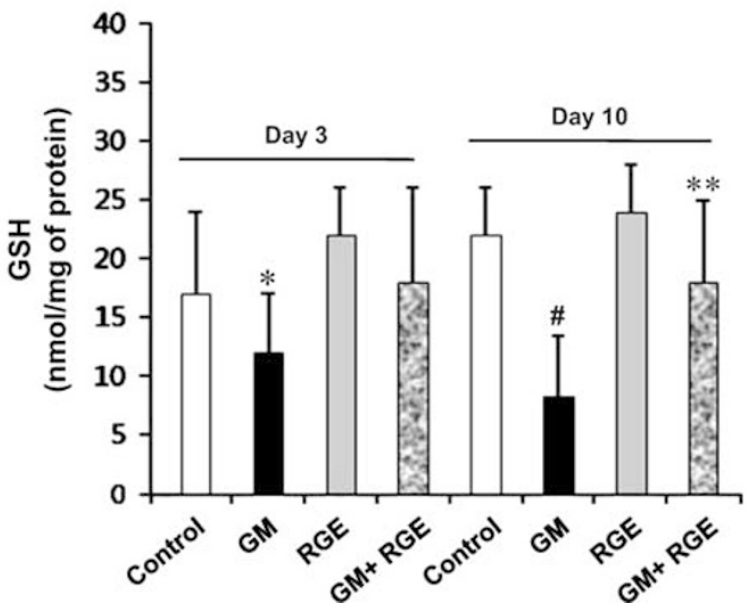

Figure 14 Effect of RGE on oxidative stress status in GM nephrotoxicity. Urinary excretion of 8-OH-dG is increased in GM group on day 3s and 10, and is alleviated in GM + RGE group (a). Decreased GSH level in renal cortex in GM group is also ameliorated by RGE treatment (b). Statistical analysis is performed using one-way ANOVA followed by multiple comparison. ${ }^{*} P<0.05$ vs control at each day, ${ }^{\#} P<0.05$ vs $\mathrm{GM}$ on day 3 , ${ }^{* *} P<0.05$ vs $\mathrm{GM}$ on day 10.

cultured renal tubular cells with a reversal of the alteration in apoptosis-related protein expression induced by GM. This in vitro finding was also confirmed in animal model of GMinduced AKI, showing an increased apoptosis in renal tubular cells of kidney tissue (Figure 12) that was ameliorated in $\mathrm{GM}+$ RGE group. The beneficial effect of RGE on GM-induced apoptosis seems to be mediated by the antioxidant effect of RGE as altered expressions of apoptosis-related proteins were preceded by ROS production, and antioxidant treatment blocked the changes in these (Figure 9). There are several reports demonstrating the effects of antioxidants on GM-induced apoptosis. ${ }^{10,45}$ In our study, ROS scavenger, NOX inhibitor, and mitochondria-targeted antioxidant all reduced GM-induced apoptosis of NRK-52E cells (Figure 8).

The protective effect of RGE on GM-induced renal injury observed in our study seems not to be related to an inhibition of intracellular uptake of GM in NRK cells. Lee et al ${ }^{35}$ previously reported that RGE treatment decreased the accumulation of GM in the kidney. However, in our study, an increase in GM accumulation, which peaked at $30 \mathrm{~min}$ of GM exposure in cultured renal tubular cells, was not changed with cotreatment of RGE. The reason for the discrepancy between in vivo and in vitro studies is not certain; however, low GM concentration in ginseng-treated rat kidney can be a secondary consequence of preserved renal function in RGE-treated rats.

An amelioration of GM-induced cytotoxicity by RGE was dose dependent in renal tubular cells. RGE at 10 or $50 \mu \mathrm{g} / \mathrm{ml}$ did not provide a significant protection from an inhibition of cell growth, cytotoxicity, ROS release, and apoptosis of NRK-52E cells by GM. In our in vitro experiment, $100 \mu \mathrm{g} / \mathrm{ml}$ was a minimum concentration for the protective effect of RGE on GM-treated renal tubular cells. In addition, our preliminary in vivo experiment showed cotreatment of RGE for 10 days during daily GM injection resulted in less remarkable renoprotection (data not shown). These findings suggest that dose and duration of RGE treatment can be one of the determinants for effective prevention or treatment of GM-induced AKI.

In this study, renoprotective effect of RGE was not investigated with each active component of RGE. Extensive studies have provided that the molecular components responsible for the antioxidant property of ginseng are saponins, namely ginsenoids. Currently, different ginsenoids identified and isolated from ginseng have been reported to impose a unique effect on different cells. ${ }^{46-48}$ Ginsenoids showed different efficacy of cellular uptake according to their unique structural characters. ${ }^{49}$ For example, the uptake of ginsenoid Rh2, Rg3, and Rb1 into breast cancer cell was higher than Rh1, Re, and Rg1 that resulted in an apoptosis of breast cancer cell. ${ }^{50}$

Although a large body of in vitro and in vivo experimental evidence indicates ROS as major mediator of aminoglycoside-induced nephrotoxicity, effective antioxidant therapy including free radical scavengers available in the clinic has not been well established yet. Recent interesting attempts to use the extract from medicinal plants with antioxidant property such as diallyl sulfide or Ginko biloba demonstrated an amelioration of GM-induced AKI. ${ }^{51-53}$ These natural antioxidants may offer comparably safer alternatives to other chemical antioxidants, although they still have the problems related to nonspecificity, impurity, or potential side effect undetected yet. Nonetheless, strategies for unearthing the therapy especially using antioxidants with safety and clinical efficacy to prevent GM-induced nephrotoxicity are of great clinical interests. 
In conclusion, our data clearly demonstrated that red ginseng protected the kidney from GM-induced AKI via an amelioration of oxidative stress and apoptosis of renal tubular cells, providing another therapeutic option to prevent GM-induced nephrotoxicity.

\section{ACKNOWLEDGMENTS}

This research was supported by the Bio \& Medical Technology Development Program of the National Research Foundation (NRF) funded by the Korean government (MEST) (2010-0019866, 2012R1A2A2A01013541), the Korea Society of Ginseng (2008), the Ewha Global Top5 Grant 2013 of Ewha Womans University and Hi Seoul Science (Humanities) Fellowship funded by Seoul Scholarship Foundation.

\section{DISCLOSURE/CONFLICT OF INTEREST}

The authors declare no conflict of interest.

1. Edson RS, Terrell CL. The aminoglycosides. Mayo Clinic Proc 1999;74: 519-528.

2. Gemmell CG, Edwards DI, Fraise AP, et al. Guidelines for the prophylaxis and treatment of methicillin-resistant Staphylococcus aureus (MRSA) infections in the UK. J Antimicrob Chemother 2006; 57:589-608.

3. Mingeot-Leclercq MP, Tulkens PM. Aminoglycosides: nephrotoxicity. Antimicrob Agents Chemother 1999;43:1003-1012.

4. Humes HD. Aminoglycoside nephrotoxicity. Kidney Int 1988;33: 900-911.

5. Meyer RD. Risk factors and comparisons of clinical nephrotoxicity of aminoglycosides. Am J Med 1986:80:119-125.

6. Lopez-Novoa JM, Quiros $Y$, Vicente $L$, et al. New insights into the mechanism of aminoglycoside nephrotoxicity: an integrative point of view. Kidney Int 2011;79:33-45.

7. Maldonado PD, Barrera D, Rivero I, et al. Antioxidant S-allylcysteine prevents gentamicin-induced oxidative stress and renal damage. Free Radic Biol Med 2003;35:317-324.

8. Laurent G, Carlier MB, Rollman B, et al. Mechanism of aminoglycosideinduced lysosomal phospholipidosis: in vitro and in vivo studies with gentamicin and amikacin. Biochem Pharmacol 1982;31:3861-3870.

9. Klotman PE, Yarger WE. Reduction of renal blood flow and proximal bicarbonate reabsorption in rats by gentamicin. Kidney Int 1983;24 638-643.

10. Lee KE, Kim EY, Kim CS, et al. Macrophage-stimulating protein attenuates gentamicin-induced inflammation and apoptosis in human renal proximal tubular epithelial cells. Biochem Biophys Res Commun 2013;434:527-533.

11. Sha SH, Schacht J. Formation of reactive oxygen species following bioactivation of gentamicin. Free Radic Biol Med 1999;26:341-347.

12. Nakajima T, Hishida A, Kato A. Mechanisms for protective effects of free radical scavengers on gentamicin-mediated nephropathy in rats. Am J Physiol Renal Physiol 1994;266:F425-F431.

13. Liu Z, Li W, Li X, et al. Antidiabetic effects of malonyl ginsenosides from Panax ginseng on type 2 diabetic rats induced by high-fat diet and streptozotocin. J Ethnopharmacol 2013;145:233-240.

14. Kim JH. Cardiovascular diseases and Panax ginseng: a review on molecular mechanisms and medical applications. J Ginseng Res 2012; 36:16-26.

15. Kang $\mathrm{S}$, Min H. Ginseng, the 'Immunity Boost': the effects of Panax ginseng on immune system. J Ginseng Res 2012;36:354-368.

16. Cho $\mathrm{IH}$. Effects of Panax ginseng in neurodegenerative diseases. J Ginseng Res 2012;36:342-353.

17. Yokozawa T, Dong E. Role of ginsenoside-Rd in cisplatin-induced renal injury: special reference to DNA fragmentation. Nephron 2001;89: 433-438.

18. Im GJ, Chang JW, Choi J, et al. Protective effect of Korean red ginseng extract on cisplatin ototoxicity in HEl-OC1 auditory cells. Phytother Res 2010;24:614-621.

19. Lee $\mathrm{JH}, \mathrm{Cho} \mathrm{SH}$. Korean red ginseng extract ameliorates skin lesions in NC/Nga mice: an atopic dermatitis model. J Ethnopharmacol 2011; 133:810-817.
20. Yu MA, Shin KS, Kim JH, et al. HGF and BMP-7 ameliorate high glucose-induced epithelial-to-mesenchymal transition of peritoneal mesothelium. J Am Soc Nephrol 2009;20:567-581.

21. Ryu ES, Kim MJ, Shin HS, et al. Uric acid-induced phenotypic transition of renal tubular cells as a novel mechanism of chronic kidney disease. Am J Physiol Renal Physiol 2013;304:F471-F480.

22. Rizzi MD, Hirose K. Aminoglycoside ototoxicity. Curr Opin Otolaryngol Head Neck Surg 2007;15:352-357.

23. Cuzzocrea $S$, Mazzon E, Dugo L, et al. A role for superoxide in gentamicin-mediated nephropathy in rats. Eur J Pharmacol 2002;450: 67-76.

24. Bledsoe G, Crickman S, Mao J, et al. Kallikrein/kinin protects against gentamicin-induced nephrotoxicity by inhibition of inflammation and apoptosis. Nephrol Dial Transplant 2006;21:624-633.

25. Kim WK, Song SY, Oh WK, et al. Wound-healing effect of ginsenoside Rd from leaves of Panax ginseng via cyclic AMP-dependent protein kinase pathway. Eur J Pharmacol 2013;702:285-293.

26. Hong YJ, Kim N, Lee K, et al. Korean red ginseng (Panax ginseng) ameliorates type 1 diabetes and restores immune cell compartments. J Ethnopharmacol 2012;144:225-233.

27. Lee DC, Lau AS. Effects of Panax ginseng on tumor necrosis factoralpha-mediated inflammation: a mini-review. Molecules 2011;16: 2802-2816.

28. Sung H, Jung YS, Cho YK. Beneficial effects of a combination of Korean red ginseng and highly active antiretroviral therapy in human immunodeficiency virus type 1 -infected patients. Clin Vaccine Immunol 2009;16:1127-1131.

29. Chen $Y, X u Y, Z$ hu $Y$, et al. Anti-cancer effects of ginsenoside compound $\mathrm{K}$ on pediatric acute myeloid leukemia cells. Cancer Cell Int 2013;13:24-30.

30. Rimar S, Lee-Mengel M, Gillis CN. Pulmonary protective and vasodilator effects of a standardized Panax ginseng preparation following artificial gastric digestion. Pulm Pharmacol 1996;9:205-209.

31. Park JS, Park EM, Kim DH, et al. Anti-inflammatory mechanism of ginseng saponins in activated microglia. J Neuroimmunol 2009;209: 40-49.

32. Keum YS, Park KK, Lee JM, et al. Antioxidant and anti-tumor promoting activities of the methanol extract of heat-processed ginseng. Cancer Lett 2000;150:41-48.

33. El-Khayat Z, Hussein J, Ramzy T, et al. Antidiabetic antioxidant effect of Panax ginseng. J Med Plants Res 2011;5:4616-4620.

34. Qadir Ml, Tahir $\mathrm{M}$, Lone $\mathrm{KP}$, et al. Protective role of ginseng against gentamicin induced changes in kidney of albino mice. J Ayub Med Coll Abbottabad 2011;23:53-57.

35. Lee YK, Chin YW, Choi YH. Effects of Korean red ginseng extract on acute renal failure induced by gentamicin and pharmacokinetic changes by metformin in rats. Food Chem Toxicol 2013;59:153-159.

36. Kalkan Y, Kapakin KA, Kara A, et al. Protective effect of Panax ginseng against serum biochemical changes and apoptosis in kidney of rats treated with gentamicin sulphate. J Mol Histol 2012;43:603-613.

37. Park $\mathrm{S}$, Yeo $\mathrm{M}$, Jin $\mathrm{JH}$, et al. Inhibitory activities and attenuated expressions of 5-LOX with red ginseng in Helicobacter pylori-infected gastric epithelial cells. Dig Dis Sci 2007;52:973-982.

38. Joo KR, Shin HP, Cha JM, et al. Effect of Korean red ginseng on superoxide dismutase inhibitor-induced pancreatitis in rats: a histopathologic and immunohistochemical study. Pancreas 2009;38: 661-666.

39. Dong GZ, Jang EJ, Kang SH, et al. Red ginseng abrogates oxidative stress via mitochondria protection mediated by LKB1-AMPK pathway. BMC Complement Altern Med 2013;13:64-73.

40. Ye R, Zhang X, Kong X, et al. Ginsenoside Rd attenuates mitochondrial dysfunction and sequential apoptosis after transient focal ischemia. Neuroscience 2011;178:169-180.

41. Zhang HA, Wang M, Zhou J, et al. Protective effect of ginsenoside against acute renal failure and expression of tyrosine hydroxylase in the locus coeruleus. Physiol Res 2010;59:61-70.

42. Doh KC, Lim SW, Piao SG, et al. Ginseng treatment attenuates chronic cyclosporine nephropathy via reducing oxidative stress in an experimental mouse model. Am J Nephrol 2013;37:421-433.

43. Mcllwain DR, Berger T, Mak TW. Caspase functions in cell death and disease. Cold Spring Harb Perspect Biol 2013;5:a008656-a008685.

44. Kuwana T, Newmeyer DD. Bcl-2-family proteins and the role of mitochondria in apoptosis. Curr Opin Cell Biol 2003;15:691-699. 
45. Ojano-Dirain CP, Antonelli PJ. Prevention of gentamicin-induced apoptosis with the mitochondria-targeted antioxidant mitoquinone. Laryngoscope 2012;122:2543-2548.

46. Wang H, Yu P, Gou H, et al. Cardioprotective effects of 20(S) Ginsenoside Rh2 against doxorubicin-induced cardiotoxicity in vitro and in vivo. Evid Based Complement Alternat Med 2012;2012: 506214-506222.

47. Nag SA, Qin JJ, Wang W, et al. Ginsenosides as anticancer agents: in vitro and in vivo activities, structure-activity relationships, and molecular mechanisms of action. Front Pharmacol 2012;3:25-43.

48. Liu WK, Xu SX, Che CT. Anti-proliferative effect of ginseng saponins on human prostate cancer cell line. Life Sci 2000;67:1297-1306.

49. Ha YW, Ahn KS, Lee JC, et al. Validated quantification for selective cellular uptake of ginsenosides on MCF-7 human breast cancer cells by liquid chromatography-mass spectrometry. Anal Bioanal Chem 2010;396:3017-3025.

50. Lee Jl, Ha YW, Choi TW, et al. Cellular uptake of ginsenosides in Korean white ginseng and red ginseng and their apoptotic activities in human breast cancer cells. Planta Med 2011;77:133-140.

51. Pedraza-Chaverri J, Maldonado PD, Barrera D, et al. Protective effect of diallyl sulfide on oxidative stress and nephrotoxicity induced by gentamicin in rats. Mol Cell Biochem 2003;254:125-130.

52. Naidu MU, Shifow AA, Kumar KV, et al. Ginkgo biloba extract ameliorates gentamicin-induced nephrotoxicity in rats. Phytomedicine 2000;7:191-197.

53. Ali BH. Agents ameliorating or augmenting experimental gentamicin nephrotoxicity: some recent research. Food Chem Toxicol 2003;41: 1447-1452. 